\title{
Early and midterm outcomes of left pulmonary artery angioplasty using an anterior wall flap of the main pulmonary artery in tetralogy of Fallot repair
}

\author{
Hyungtae Kim, MD, ${ }^{\mathrm{a}}$ Si Chan Sung, MD, ${ }^{\mathrm{a}}$ Yun Hee Chang, MD, ${ }^{\mathrm{b}}$ Hyoung Doo Lee, MD, ${ }^{\mathrm{c}}$ and \\ Ji Ae Park, $\mathrm{MD}^{\mathrm{c}}$
}

Objectives: Postoperative left pulmonary artery (LPA) kinking is problematic in repair of tetralogy of Fallot (TOF). We used angioplasty of the proximal LPA with an anterior wall flap of the main pulmonary artery (MPA) to prevent this problem.

\begin{abstract}
Methods: We have used an anterior wall of the MPA as a flap for LPA angioplasty in 42 patients with TOF and pulmonary stenosis (26 males and 16 females) since February 2007. During the same period, 116 patients underwent total repair of TOF with pulmonary stenosis. The median age was 7.1 months (range, 3-88.8), and the median weight was $8.4 \mathrm{~kg}$ (range, 5-27). The indications for LPA angioplasty were acute-angle proximal LPA in $17(40.5 \%)$, proximal LPA stenosis in $6(14.3 \%)$, acute-angle and stenotic proximal LPA in 18 $(43 \%)$, and short and small distal MPA in 1 patient. The patches used for MPA and LPA reconstruction were glutaraldehyde-treated autologous pericardium in 34 and bovine pericardium in 8 patients.
\end{abstract}

Results: No operative or late death occurred. The mean follow-up duration after surgery was $26.4 \pm 18.6$ months (range, 0.5-67). During the follow-up period, reoperation for LPA stenosis or kinking was not required in any patient; however, balloon angioplasty was performed with good results in 4 patients $(9.5 \%)$. No postoperative kinking of the proximal LPA occurred. Echocardiography or computed tomography angiography at the recent follow-up visit demonstrated good branch pulmonary arteries in all patients.

Conclusions: Angioplasty of the proximal LPA using an anterior wall flap of the MPA in the patients with TOF and pulmonary stenosis is an effective method in the management of acute angle and/or stenosis of LPA without postoperative kinking. (J Thorac Cardiovasc Surg 2014;148:2597-601)

\begin{abstract}
Although numerous published reports have demonstrated excellent immediate and long-term outcomes after surgical correction of tetralogy of Fallot (TOF), ${ }^{1-3}$ branch pulmonary arterial obstruction related to postoperative left pulmonary artery (LPA) kinking is 1 of the most frequent indications for reoperation or reintervention. ${ }^{4-6}$ It is encountered in many patients with TOF undergoing reoperation for other reasons. $^{7,8}$ Several therapeutic methods have been addressed to solve this problem. ${ }^{4,6,9,10}$ We report angioplasty of the proximal LPA using the anterior wall of the main pulmonary artery (MPA) as a flap for avoiding postoperative LPA kinking.
\end{abstract}

\footnotetext{
From the Department of Thoracic and Cardiovascular Surgery, ${ }^{\mathrm{a}}$ Research Institute for Convergence of Biomedical Science and Technology, Pusan National University Yangsan Hospital, Gyeongsangnam-do, Republic of Korea; Department of

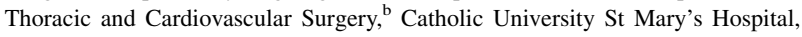
Seoul, Republic of Korea; and Department of Pediatrics, ${ }^{\mathrm{c}}$ Pusan National University Yangsan Hospital, Gyeongsangnam-do, Republic of Korea.

Supported by a 2013 research grant from Pusan National University Yangsan Hospital.

Disclosures: Authors have nothing to disclose with regard to commercial support.

Received for publication Aug 7, 2013; revisions received Oct 6, 2013; accepted for publication Oct 26, 2013; available ahead of print Dec 11, 2013.

Address for reprints: Si Chan Sung, MD, Department of Thoracic and Cardiovascular Surgery, Pusan National University Yangsan Hospital, Mulgeum-eup, Yangsan-si, Gyeongsangnam-do 626-770, Republic of Korea (E-mail: scsung21@ hanmail.net). $0022-5223 / \$ 36.00$

Copyright (c) 2014 by The American Association for Thoracic Surgery

http://dx.doi.org/10.1016/j.jtcvs.2013.10.060
}

\section{METHODS \\ Patients}

The institutional review board at Pusan National University Yangsan Hospital approved the present study (approval no. 05-2013-025). We have adopted an anterior wall flap of the MPA for LPA angioplasty in 42 patients with TOF and pulmonary stenosis (26 males and 16 females) since February 2007. During the same period, 116 patients underwent total repair of TOF and pulmonary stenosis (42 of 116 [36.2\%]). The median age was 7.1 months (range, 3-88.8), and the median weight was $8.4 \mathrm{~kg}$ (range, 5-27). A total of 18 palliative procedures were performed before TOF repair in 16 of the 42 patients enrolled in the present study. These included right modified Blalock-Taussig shunt in 3, left modified Blalock-Taussig shunt in 5, balloon pulmonary valvuloplasty in 9, and surgical infundibulectomy in 1 patient. A total of 16 patients underwent transannular patch enlargement of the right ventricular outflow tract. The indications for LPA angioplasty were an acute-angle proximal LPA in 17 (40.5\%), proximal LPA stenosis in $6(14.3 \%)$, acute-angle and stenotic proximal LPA in $18(43 \%)$, and a short and small distal MPA in 1 patient $(2.4 \%)$.

\section{Surgical Technique}

When a patient with TOF and pulmonary stenosis has an acute-angle and stenotic proximal LPA, we have used an anterior wall flap of the MPA for proximal LPA angioplasty to augment the posterior wall of the distal MPA and release the acute angle of the proximal LPA. A right-sided longitudinal incision was made at the MPA, and this incision was extended to the LPA inferior margin crossing the MPA-LPA junction (Figure 1, B). The anterior wall flap of the MPA was unfolded toward the LPA and anastomosed to the incision at the under surface of the LPA to enlarge the posterior wall of the distal MPA and alleviate the acute angle of the MPA-LPA junction using fine polypropylene suture (Figure $1, C$ ). A small incision was added to 


\section{Abbreviations and Acronyms \\ LPA $=$ left pulmonary artery \\ $\mathrm{MPA}=$ main pulmonary artery \\ $\mathrm{RPA}=$ right pulmonary artery \\ TOF $=$ tetralogy of Fallot}

prevent stenosis of the suture site at the LPA (Figure 1,D). The MPA and LPA incision sites were covered with a reversed D-shaped patch using continuous suture under arrested heart or beating heart conditions (Figure 1,E). The patches used for this technique were glutaraldehydetreated autologous pericardium in 34 and bovine pericardium in 8 patients. After this procedure, we could observe an obtuse-angle and broad proximal LPA (Figure 1, F). Follow-up computed tomography angiography also showed the same findings (Figure 1, F, small box).

Proximal right pulmonary artery (RPA) stenosis was present in 9 patients. In these cases, a longitudinal incision was made from the MPA incision site to
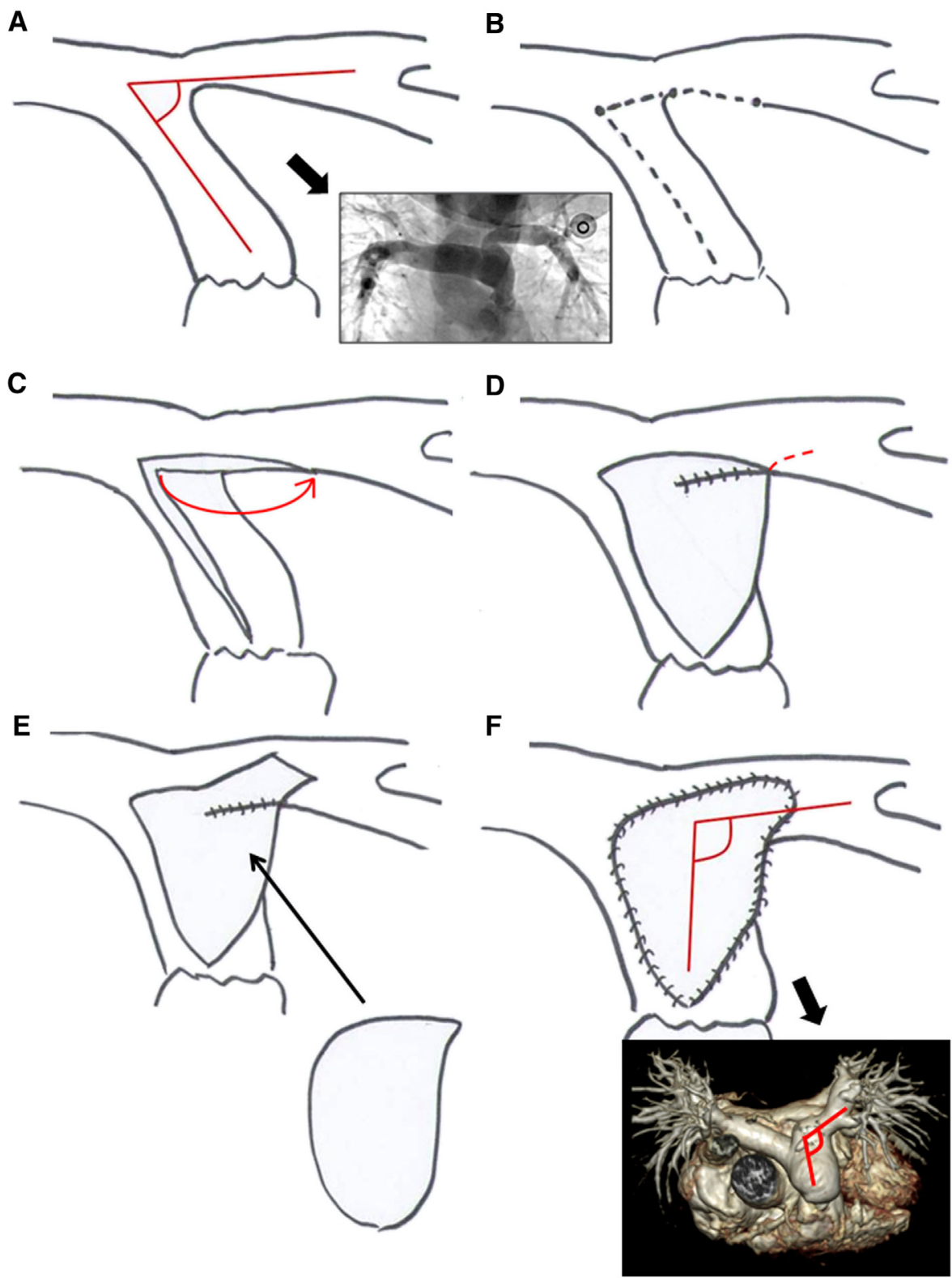

FIGURE 1. Schematic drawings of (A) left pulmonary artery (LPA) angioplasty (inset) of an acute-angle and stenotic proximal LPA, (B) a right-sided longitudinal incision extending to the LPA inferior margin and crossing the main pulmonary artery (MPA)-LPA junction, (C) an anterior wall flap of the MPA unfolded toward a LPA, (D) the addition of a small incision to prevent stenosis of the suture site at LPA, (E) coverage of the MPA and LPA incision sites with a reversed D-shaped patch, and (F) an obtuse-angle and broad proximal LPA (inset). 
the proximal RPA for proximal RPA enlargement (Figure 2, B). RPA patch angioplasty was performed, followed by MPA and LPA angioplasty using the anterior wall flap of the MPA (Figure 2, $C$ to $E$ ). The patches used for RPA angioplasty were glutaraldehyde-treated autologous pericardium in 4 , bovine pericardium in 4 , and fresh autologous pericardium in 1 patient.

\section{Statistical Analysis}

The data were collected and managed using Microsoft Excel 2007 (Microsoft, Redmond, Wash) and analyzed using the Statistical Package for Social Sciences, version 17.0 (SPSS, Inc, Chicago, Ill). The categorical variables were compared using the chi-square test and continuous variables using the Student $t$ test. The Kaplan-Meier method was used to analyze freedom from reintervention. Probability values of less than .05 were considered significant.

\section{RESULTS}

No operative or late deaths occurred. The mean cardiopulmonary bypass time was $171 \pm 29$ minutes (range, 114-262), and the mean aortic crossclamp time was 114 \pm 20 minutes (range, 68-155). The mean postoperative ventilator support time was $30.3 \pm 24.1$ hours (range,
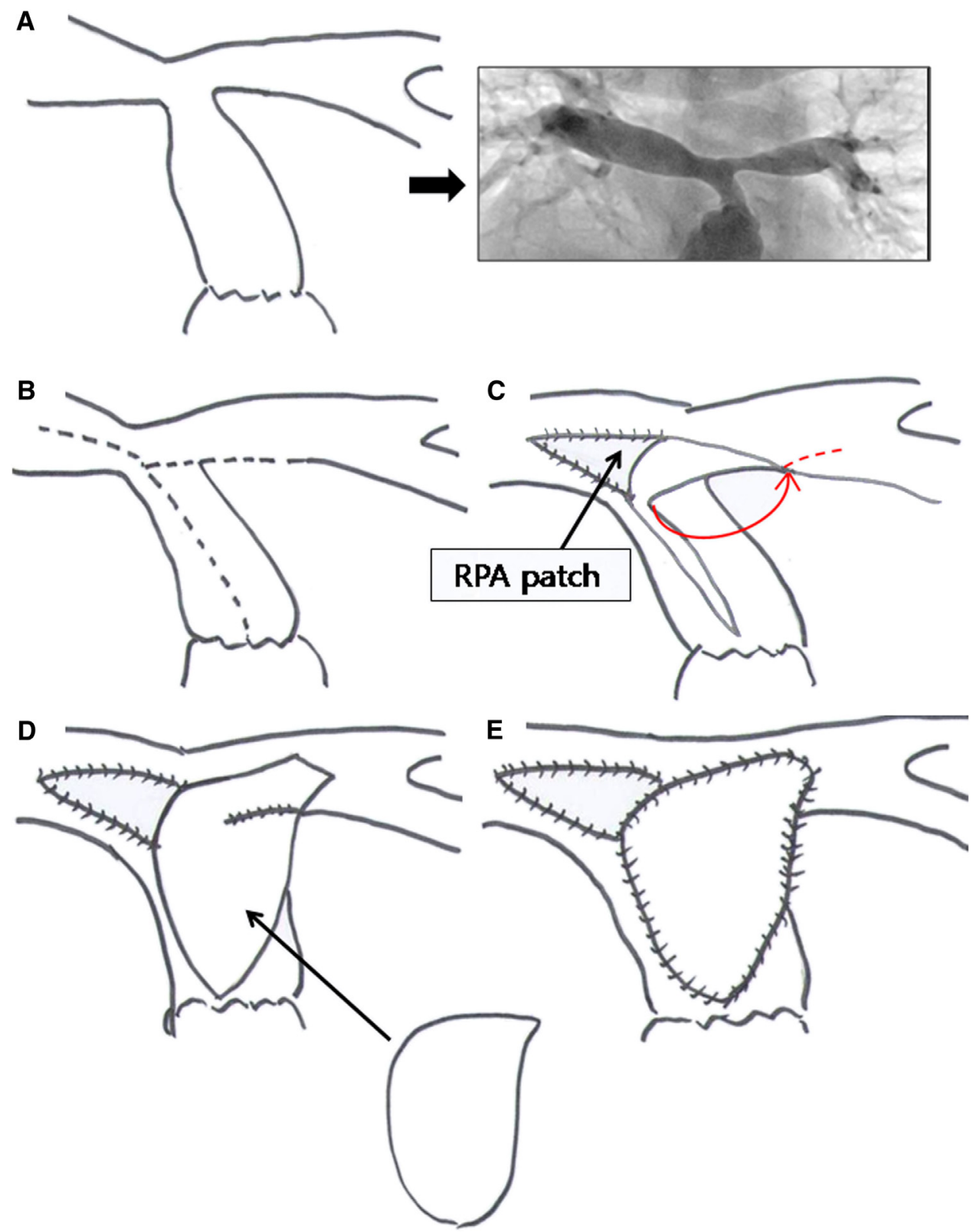

FIGURE 2. Schematic drawings of simultaneous left pulmonary artery (LPA) and right pulmonary artery (RPA) angioplasty showing (A) proximal stenosis of the RPA and LPA, (B) a longitudinal incision at the proximal RPA from main pulmonary artery (MPA) incision site, (C-E) RPA angioplasty followed by MPA and LPA angioplasty using an anterior wall flap of the MPA. 
TABLE 1. Risk factor analysis for postoperative reintervention for left pulmonary artery stenosis

\begin{tabular}{|c|c|c|c|}
\hline \multirow[b]{2}{*}{ Risk factor } & \multicolumn{2}{|c|}{ Postoperative reintervention } & \multirow[b]{2}{*}{$P$ value } \\
\hline & Yes $(n=4)$ & No $(n=38)$ & \\
\hline Male gender & $4 / 4$ & $22 / 38$ & .099 \\
\hline Age (mo) & $8.45 \pm 3.47$ & $11.3 \pm 14.5$ & .702 \\
\hline Weight $(\mathrm{kg})$ & $8.9 \pm 1.0$ & $8.7 \pm 3.5$ & .882 \\
\hline $\begin{array}{l}\text { Both LPA stenosis and } \\
\text { kinking }\end{array}$ & $3 / 4$ & $15 / 38$ & .345 \\
\hline $\begin{array}{l}\text { Patch used for LPA } \\
\text { angioplasty }\end{array}$ & & & .750 \\
\hline $\begin{array}{l}\text { Autologous } \\
\text { pericardium }\end{array}$ & 3 & 31 & \\
\hline Bovine & 1 & 7 & \\
\hline $\begin{array}{l}\text { Preoperative palliative } \\
\text { operation }\end{array}$ & $2 / 4$ & $6 / 38$ & .097 \\
\hline $\begin{array}{l}\text { Concomitant RPA } \\
\text { angioplasty }\end{array}$ & $1 / 4$ & $8 / 38$ & .855 \\
\hline Transannular patch & $3 / 4$ & $13 / 38$ & .276 \\
\hline CPB time (min) & $195.8 \pm 21.3$ & $168.9 \pm 29.0$ & .080 \\
\hline ACC time (min) & $126.0 \pm 27.2$ & $112.8 \pm 18.9$ & .209 \\
\hline $\begin{array}{l}\text { Postoperative ventilator } \\
\text { support (h) }\end{array}$ & $20.0 \pm 14.5$ & $31.4 \pm 24.7$ & .376 \\
\hline Hospital stay (d) & $8.8 \pm 2.9$ & $11.5 \pm 6.3$ & .391 \\
\hline
\end{tabular}

6-161). The mean hospital stay was $11.3 \pm 6.1$ days (range, $7-35)$. Eight complications occurred in 6 patients $(14.2 \%)$ postoperatively: chylothorax in 2, right pleural effusion requiring chest tube insertion in 3 , and postoperative transient arrhythmia in 3 patients. The mean follow-up duration was $27.4 \pm 19.9$ months (range, 0.5-73). During the followup period, reoperation for LPA stenosis was not required in any patient; however, balloon angioplasty for LPA stenosis was performed with good results in 4 patients $(9.5 \%)$. Of the patients who underwent balloon angioplasty, 1 patient was found to have left modified Blalock-Taussig shunt site stenosis. We analyzed the risk factor for postoperative balloon angioplasty for LPA stenosis, including age at surgery, LPA angioplasty indication, LPA patch, preoperative palliative procedure, RPA angioplasty, transannular patch enlargement, cardiopulmonary bypass time, and aortic crossclamp time. The analysis did not reveal any specific risk factor (Table 1). The freedom from reintervention was $94.3 \%, 94.3 \%$, and $85.9 \%$ at 6 months, 1 year, and 3 years, respectively (Figure 3, A). No postoperative kinking of the proximal LPA occurred. Echocardiography or computed tomography angiography at the most recent follow-up visit demonstrated good branch pulmonary arteries in all patients.

We compared the outcomes of the present 42 patients with those of previous data from our hospital. A total of 17 patients had undergone LPA angioplasty using other techniques (Heineke-Mickulicz type repair in 8, 2-patch technique in 4, 1-patch technique in 3, proximal LPA division and relocation at MPA in 1, and intimal excision in 1 patient) from January 2004 to December 2006. The median age at surgery was 6.8 months (range, 1.7-23), and the mean follow-up duration was $72.6 \pm 17.7$ months (range, 36.398.9). No difference was found between the 2 groups in the reintervention rate for LPA stenosis (Figure 3, $B$; $P=.885, \log$-rank test). However, of the 17 patients who had undergone the previous techniques, $6(35.3 \%)$ had proximal LPA kinking with or without stenosis.

\section{DISCUSSION}

Pulmonary artery stenosis, especially proximal LPA stenosis, has been commonly observed in many patients requiring reoperation after total correction of $\mathrm{TOF}^{4-6}$ The management of LPA narrowing is a critical point in the treatment of TOF. This stenosis and acute angle can be congenital but can also be acquired as a consequence of preoperative palliative procedures. ${ }^{11}$ The postoperative LPA obstruction caused by stenosis or kinking will aggravate pulmonary regurgitation and will eventually result in
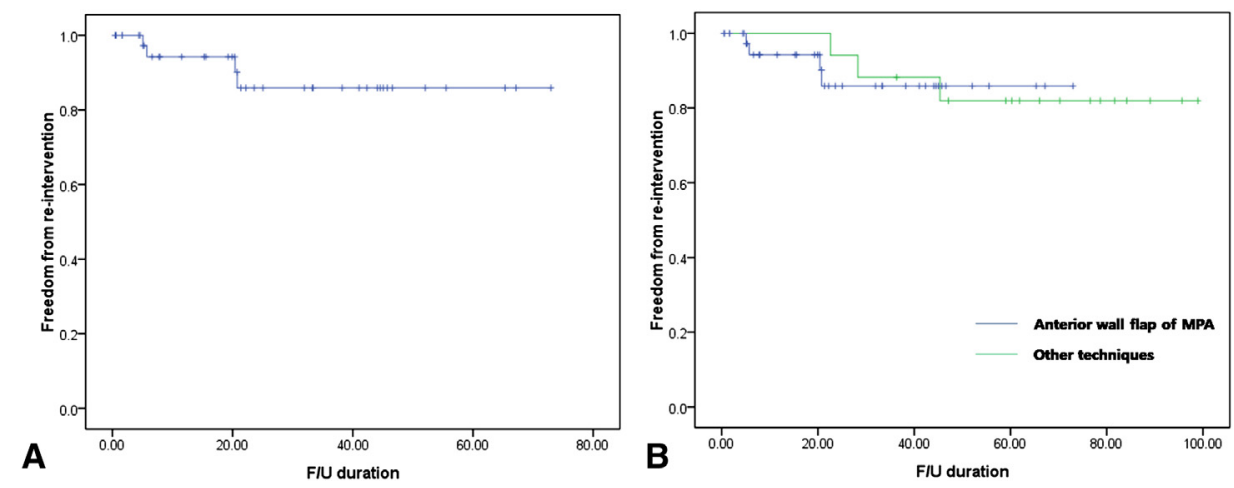

FIGURE 3. Freedom from reintervention (A) in the patients who had undergone left pulmonary artery (LPA) angioplasty using an anterior wall flap of the main pulmonary artery $(M P A)$. B, A comparison between the patients $(\mathrm{n}=42)$ who had undergone LPA angioplasty using an anterior wall flap of the MPA and those $(\mathrm{n}=17)$ who had undergone other techniques $(P=.885$, log-rank test $) . F / U$, Follow-up. 
right ventricular enlargement. The regurgitant flow could enlarge the MPA, which will ultimately lead to compression and kinking of the LPA. Therefore, the LPA stenosis and kinking should be corrected, and great attention should be directed toward these problems during TOF repair.

Kinking of the proximal LPA is a common mechanism of postoperative LPA stenosis, because the RPA usually has the same direction as the MPA, and the LPA takes off at a rather acute angle in most patients with TOF (Figure 1, small box). Therefore, selection of the patch enlargement technique for LPA stenosis and/or acute angle is very important at primary complete correction of TOF. Proper patch enlargement can significantly reduce early restenosis and subsequent reoperation. If a single patch enlargement technique is used without removing the redundancy at the kink point, in particular, in patients with stenosis at the origin of the LPA, which take off at a rather acute angle, the risk of restenosis is high. ${ }^{4}$ Additional patch material in a redundant outflow tract might provide a substrate for recurrent kinking in patients with an acute-angle LPA. ${ }^{6}$ To correct LPA obstruction with an acute angle, several methods have been introduced, including a 2-patch technique, reimplantation of the LPA into the pulmonary trunk, and widening of the stenotic back wall by sewing the adjacent edges of the LPA and MPA together. ${ }^{4,6,9}$ In our study, we used an anterior wall flap of the MPA for LPA angioplasty. Using this technique, the posterior back wall of the distal MPA can be maximally widened, and the opening of the LPA can be translocated to the left side as far as necessary, which can prevent kinking of the LPA and release LPA stenosis very effectively. Furthermore, the development of postoperative LPA stenosis was minimized by patch enlargement of the newly created LPA opening. After LPA angioplasty with an anterior wall flap of the MPA, the LPA origin became wider, with an obtuse angle (Figure 1,F). Another advantage of this technique was that postoperative LPA stenosis after our LPA angioplasty technique was very amenable to balloon dilatation. When LPA obstruction is caused entirely or in part by kinking, simple balloon dilatation is unlikely to be effective, and stent insertion should be considered. ${ }^{6}$ However, all 4 cases with postoperative LPA stenosis in our study were amenable to balloon angioplasty without stent placement, because the LPA stenosis had no kinking component. We also compared the outcomes of these patients with those of 17 patients who had undergone treatment using other techniques. Although we could not find any difference between the 2 groups in the reintervention rate for LPA steno- sis, the present group had a superior result in postoperative LPA kinking (6 of 17 [35.3\%] vs 0 of $42[0 \%]$ ).

The present study had several limitations, including a relatively short follow-up period, that it was a singleinstitutional study, and the lack of a proper comparative group. The present study was neither a prospective nor case-controlled study; thus, the patients were not matched for demographic data or concomitant surgical procedures. However, reoperation for LPA stenosis was not required in any patient. The reintervention rate (4 of 42 [9.5\%]) for LPA stenosis was also comparable to that from other reports. ${ }^{4,5}$ Also, no postoperative kinking of the LPA stenosis occurred, which was 1 of the most important points in LPA angioplasty.

\section{CONCLUSIONS}

Angioplasty of the proximal LPA using the anterior wall flap of the MPA in patients with an acute angle and/or a stenotic LPA origin is a highly effective method in TOF repair to avoid postoperative kinking of the LPA. However, longterm follow-up is still required.

\section{References}

1. Murphy JG, Gersh BJ, Mair DD, Fuster V, McGoon MD, Ilstrup DM, et al. Longterm outcome in patients undergoing surgical repair of tetralogy of Fallot. N Engl J Med. 1993;329:593-9.

2. Rosenthal A, Behrendt D, Sloan H, Ferguson P, Snedecor SM, Schork A. Longterm prognosis (15 to 26 years) after repair of tetralogy of Fallot: I. Survival and symptomatic status. Ann Thorac Surg. 1984;38:151-6.

3. Waien SA, Liu PP, Ross BL, Williams WG, Webb GD, McLaughlin PR. Serial follow-up of adults with repaired tetralogy of Fallot. J Am Coll Cardiol. 1992 20:295-300.

4. Faidutti B, Christenson JT, Beghetti M, Friedli B, Kalangos A. How to diminish reoperation rates after initial repair of tetralogy of Fallot? Ann Thorac Surg. 2002;73:96-101

5. Hennein HA, Mosca RS, Urcelay G, Crowley DC, Bove EL. Intermediate results after complete repair of tetralogy of Fallot in neonates. J Thorac Cardiovasc Surg. 1995; 109:332-42. 44; discussion 42-3

6. McElhinney DB, Parry AJ, Reddy VM, Hanley FL, Stanger P. Left pulmonary artery kinking caused by outflow tract dilatation after transannular patch repair of tetralogy of Fallot. Ann Thorac Surg. 1998;65:1120-6.

7. Uretzky G, Puga FJ, Danielson GK, Hagler DJ, McGoon DC. Reoperation after correction of tetralogy of Fallot. Circulation. 1982;66:I202-8.

8. Zhao HX, Miller DC, Reitz BA, Shumway NE. Surgical repair of tetralogy of Fallot: long-term follow-up with particular emphasis on late death and reoperation. J Thorac Cardiovasc Surg. 1985;89:204-20.

9. Chowdhury UK, Agarwal S, Kothari SS, Airan B. Alternative approach for angioplasty of stenosed left pulmonary artery following intracardiac repair of tetralogy of Fallot. Heart Lung Circ. 2002;11:121-5.

10. Lee C, Jeon Y, Lee T, Lee SK, Baek MJ, Kim SC, et al. A new technique of angioplasty of the left pulmonary artery using an autologous main pulmonary artery flap. Korean J Thorac Cardiovasc Surg. 2003;36:255-60.

11. Trusler GA, Miyamura H, Culham JA, Fowler RS, Freedom RM, Williams WG. Pulmonary artery stenosis following aortopulmonary anastomoses. J Thorac Cardiovasc Surg. 1981;82:398-404. 